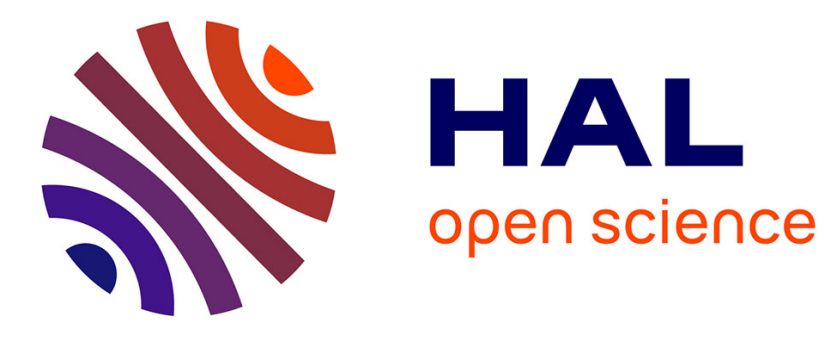

\title{
Experimental study of yawed inflow around wind turbine rotor
}

Belkheir Noura, Ivan Dobrev, Rabah Dizene, Fawaz Massouh, Sofiane Khelladi

\section{To cite this version:}

Belkheir Noura, Ivan Dobrev, Rabah Dizene, Fawaz Massouh, Sofiane Khelladi. Experimental study of yawed inflow around wind turbine rotor. Journal of Power and Energy, 2012, 226 (5), pp.664-673. $10.1177 / 0957650912445015$. hal-01086393

\section{HAL Id: hal-01086393 https://hal.science/hal-01086393}

Submitted on 13 Feb 2015

HAL is a multi-disciplinary open access archive for the deposit and dissemination of scientific research documents, whether they are published or not. The documents may come from teaching and research institutions in France or abroad, or from public or private research centers.
L'archive ouverte pluridisciplinaire HAL, est destinée au dépôt et à la diffusion de documents scientifiques de niveau recherche, publiés ou non, émanant des établissements d'enseignement et de recherche français ou étrangers, des laboratoires publics ou privés. 


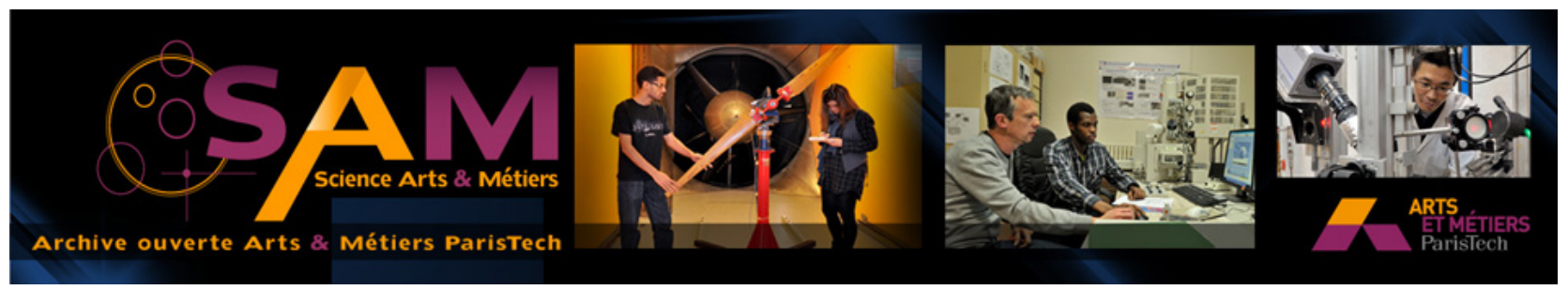

Science Arts \& Métiers (SAM)

is an open access repository that collects the work of Arts et Métiers ParisTech researchers and makes it freely available over the web where possible.

This is an author-deposited version published in: http://sam.ensam.eu Handle ID: .http://hdl.handle.net/10985/8967

\section{To cite this version :}

Belkheir NOURA, Ivan DOBREV, Rabah DIZENE, Fawaz MASSOUH, Sofiane KHELLADI Experimental study of yawed inflow around wind turbine rotor - Journal of Power and Energy Vol. 226, n5, p.664-673 - 2012 


\title{
Experimental study of yawed inflow around wind turbine rotor
}

\author{
Belkheir Noura', Ivan Dobrev², Rabah Dizene', \\ Fawaz Massouh $^{2}$ and Sofiane Khelladi ${ }^{2}$
}

\begin{abstract}
In this article, we present an experimental study in a wind tunnel of a three-bladed, Rutland 503 model, horizontal axis yawed wind turbine. Power measurement and an exploration downstream wake of the turbine using particle image velocimetry measurements are performed. The variation of power coefficient as a function of rotational velocity is presented for different yaw angles. The results show a loss of power from the wind turbine when the yaw angle increases. The velocity field of the downstream wake of the rotor is presented in an azimuth plane, which passes through the symmetry axis of the rotor. The instantaneous velocity field is measured and recorded to allow for obtaining the averaged velocity field. The results also show variations in the wake downstream due to decelerating flow caused by the yawed turbine rotor. Analysis of this data shows that the active control of yaw angles could be an advantage to preserve the power from the wind turbine and that details near rotor wake are important for wake theories and to predict the performance of wind turbines as well.
\end{abstract}

\section{Keywords}

Wind energy, horizontal axis wind turbine rotor, wind tunnel, yawed inflow, particle image velocimetry

\section{Introduction}

The aerodynamics of wind turbine remains a difficult area for research, yet it is crucial for wind energy. The operating conditions depend on several factors such as wind direction and velocity. It is, however, impossible to have the wind turbine axis permanently aligned toward the wind direction, and hence, the flow is often yaw. Under these conditions, the flow is very complex and it is very difficult to obtain the performance of the wind turbine and the velocity field downstream the rotor, with Navier-Stokes equation solvers. The modeling of the flow within a horizontal axis wind turbine (HAWT) subjected to real-wind conditions remains difficult.

The investigation of the development of the wake downstream of the wind turbine is important for the design of these wind turbines. Therefore, it is necessary to have experimental results which could validate the calculations and adjust some parameters.

Less research work is dedicated to the investigation of the wake flow of wind turbines in yawed position within the wind tunnel; for example, the experimental investigation presented by Parkin et al. ${ }^{1}$ who studied the wake five-dimensional (5D) downstream of a wind turbine in the yawed position. However, in the later work, the vortices do not appear clearly in the results because of the large size of the studied velocity field, and therefore, it is difficult to have a sufficient spatial and temporal resolution for the development of the wake.

The blade tip vortices that exist in the wake play an important role in the aerodynamics of the turbine. They produce a very complex flow field with strong gradients. These vortices are also the major source of instability.

The particle image velocimetry (PIV) technique is a non-intrusive method which allows the measurement of the instantaneous velocity vectors in a plane.

\footnotetext{
'Centre Universitaire de Khemis Miliana, Algérie

${ }^{2}$ Arts et Métiers ParisTech, France

${ }^{3}$ USTHB LMA, Algerie

Corresponding author:

Belkheir Noura, Centre Universitaire de Khemis Miliana, Route de Thenia, Khemis Miliana, 44225 Ain Defla, Algérie.

Email: nourabelhadj@yahoo.fr
} 
However, a large number of researchers have used the PIV technique to investigate the wake of wind turbines and their results are rather qualitative; see, for instance, works of Smith et al., ${ }^{2}$ Grant and Parkin, ${ }^{3}$ and Grant et $\mathrm{al}^{4}{ }^{4}$ However, in recent years, Massouh et al., ${ }^{5}$ Massouh and Dobrev, ${ }^{6,7}$ and Dobrev et al. ${ }^{8}$ conducted many studies with the aim to determine the development of the wake behind the wind turbine and to obtain more accurate results. Very encouraging quantitative and qualitative results were found for the study of the wake downstream of this wind turbine.

This research work is a continuation of research studies conducted in Massouh and Dobrev ${ }^{7}$ and Dobrev et al. ${ }^{8}$ The objective of this research work is to first study the performance of a horizontal axis three-blade wind turbine model (Rutland 503 of the Marlec Company) of diameter $0.5 \mathrm{~m}$, depending on the yaw angle and second, investigate the velocity field of the wake downstream of yawed wind turbine rotor.

Power data are obtained by measurements of the torque produced by the wind turbine and the rotational velocity, and the instruments used are described below. Power measurements are performed for an axial flow, yaw conditions of $0^{\circ}, 15^{\circ}$, and $30^{\circ}$, and rotational velocities from 500 to $1800 \mathrm{r} / \mathrm{min}$.

The velocity field investigation of the wake downstream the rotor is acquired through the PIV technique. The measurements are performed for an axial flow and yaw angles of $10^{\circ}, 15^{\circ}$, and $30^{\circ}$, and rotational velocities of $1256,1345,1561$, and $1800 \mathrm{r} / \mathrm{min}$.

\section{Description of the experimental setup}

The experimental rig used in this study consists of the three basic components:

- the rotor of HAWT Rutland 503;

- the wind tunnel of the LMA laboratory at the Arts and Métiers Paris Tech; and

- a complete PIV measurement test bench.

\section{Tested wind turbine rotor}

The rotor used in this study is of a commercial wind turbine Rutland 503 of Marlec Company. The original wind turbine had six blades; however, three blades and the hub of the carnage have been removed to obtain a three-blade turbine (Figure 1). The diameter of this wind rotor is $50 \mathrm{~cm}$ and that of the hub $13.5 \mathrm{~cm}$. The chord line is 6.8 and $4.8 \mathrm{~cm}$ at the tip of the blade. The blades are untwisted and fitted with a constant pitch angle of $10^{\circ}$. The axis of rotation of the wind turbine is placed at a height of $70 \mathrm{~cm}$ in the middle of the test

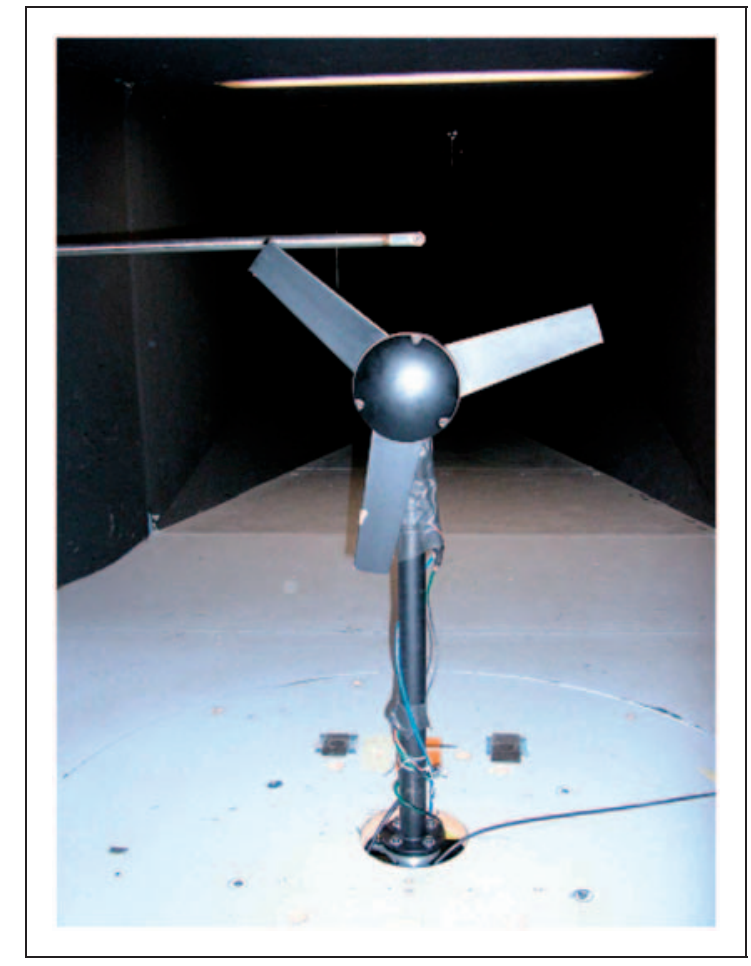

Figure I. Rutland 503 in wind tunnel, ENSAM.

section, with a mat of $3.7 \mathrm{~cm}$ diameter, to avoid the influence of ceiling and floor on the behavior of the wake and allow lasers to illuminate the investigation plan with sufficient intensity. To reduce reflections of laser radiation, the entire surface of the rotor is covered with a matt black paint. During testing, the rotation velocity is adjustable from 1200 to $1800 \mathrm{r} / \mathrm{min}$.

The rotor is mounted on a shaft (Figure 2), the latter being coupled with an electric direct current generator. The monitoring of the rotational velocity and load of the rotor is by a rheostat connected to the output of the generator coupled to the wind turbine. The model is positioned on a turntable which allows change in the position of the turbine for each test, for angles of $0^{\circ}$, $15^{\circ}$, and $30^{\circ}$ with regard to the axis of the wind tunnel.

The coupling between the rotor shaft and the generator is done via a torque meter that measures the mechanical torque and transmits a square signal for each degree. In order to locate the passage of the blade taken as a reference, an optical encoder is mounted on the shaft pinpointing the rotating target. Thus, by counting the number of signals coming from the square after the passage of the reference torque signal, we can deduce the rotor's angular position with an accuracy of $1^{\circ}$. The data acquisition from the encoder is done through an acquisition card which emits a TTL signal that is used to trigger the PIV measurements for a given azimuthal position of the rotor. 


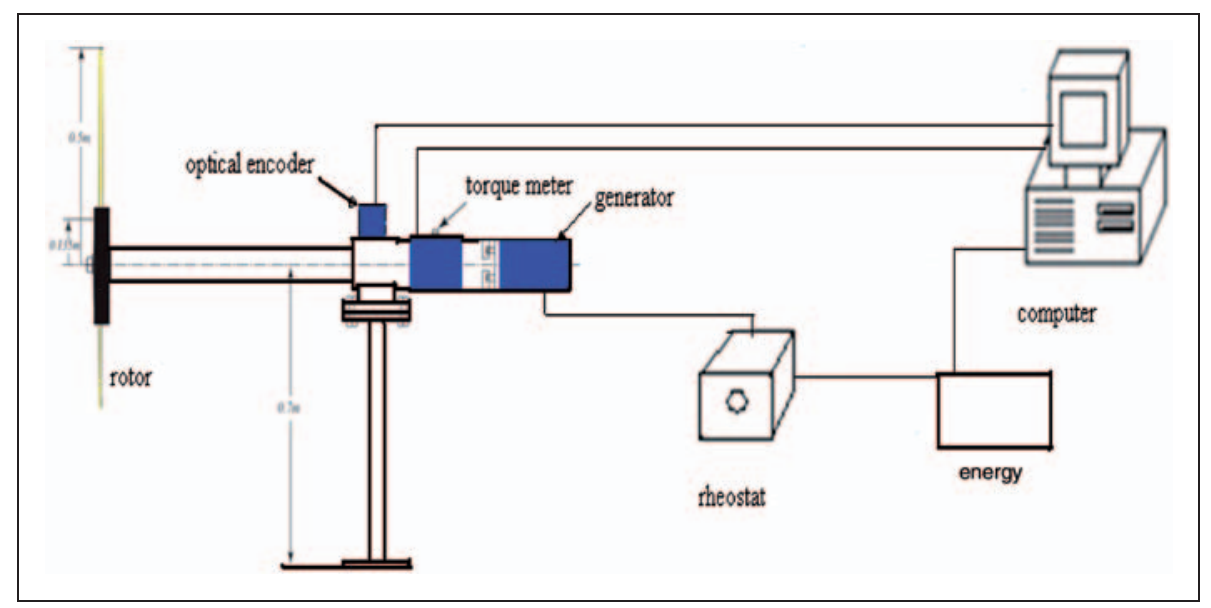

Figure 2. Experimental bench power measurement.

\section{LMA wind tunnel}

The used wind tunnel (Figure 3) is of a Prandtl type with a semi-guided vein open to atmospheric pressure and a return channel. The test section has a rectangular cross section of $1.35 \times 1.65 \mathrm{~m}^{2}$ over a length of $2 \mathrm{~m}$. The supply of the test section is made from a plenum through a convergent ratio of $1: 12.5$, thereby making the flow globally uniform. The maximum velocity in this vein is about $40 \mathrm{~m} / \mathrm{s}$.

The presence of an explorer helps to perform 3-D exploration of the velocity field in the vein. The vein is extended by a diffuser with an opening angle of about $7^{\circ}$ to prevent the separation of the flow on the walls. The back vein has a $3 \times 3 \mathrm{~m}^{2}$ square section throughout a $6 \mathrm{~m}$ length and a maximum flow velocity of about $10 \mathrm{~m} / \mathrm{s}$. The ceiling of the test section is transparent to allow the laser fixed on the top to illuminate the investigation plan with sufficient intensity.

\section{PIV measurements}

The principle of PIV method is to record on a video sensor two successive images of particles illuminated by a laser layer. ${ }^{9}$ From these two images, a field of local and instantaneous velocities is calculated using the particle motion. The measurement test bench is presented in Figure 4 PIV: particle image velocimetry. The camera used is Dantec FlowSense 4 M, Nikkor AF-S $105 \mathrm{~mm}$ $\mathrm{f} / 2.8 \mathrm{G}$ ED IF, fixed on a tilting support. Its resolution is $2048 \times 2048$ pixels with a dynamic gray level of 12 bits. The exposure time of the first image is almost instantaneous and the second image starts when the first is transferred to the storage zone. This exposure time is fixed. It represents the time needed for the camera to transfer information from the storage zone into the RAM of the computer. This transfer is done

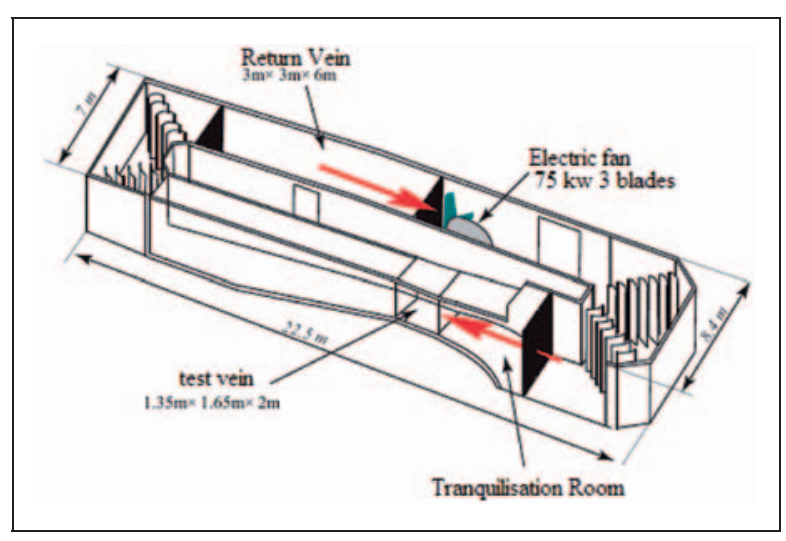

Figure 3. Wind tunnel laboratory, ENSAM, Paris Tech.

via optical fibers of about $1 \mathrm{~m}$ length, fitted with access Camera Link. The laser power is a decisive factor in the PIV measurement because it determines, together with the sensitivity of the $\mathrm{CCD}$, the minimum size of particles that can be exploited for a quality measure. The laser type is Litron Nano-L 200-15 and the energy it generates $200 \mathrm{~mJ}$. The time interval $\Delta t$, between two laser flashes, is $20 \mu$ s with a flow upstream velocity of $9.3 \mathrm{~m} / \mathrm{s}$.

The seeding of the flow is achieved through microdroplets of olive oil created by a mist generator (10F03 Dantec). They are generated upstream of the convergent wind tunnel and the waiting time necessary to homogenize the particles in the vein must be met before each measurement. The density of particles injected into the flow is decisive and the flow of the particles must be adapted to the speed of the blower. This setting is refined by a zoom on the camera, which controls the number of particles, knowing that a sufficient number of particles per interrogation window are 


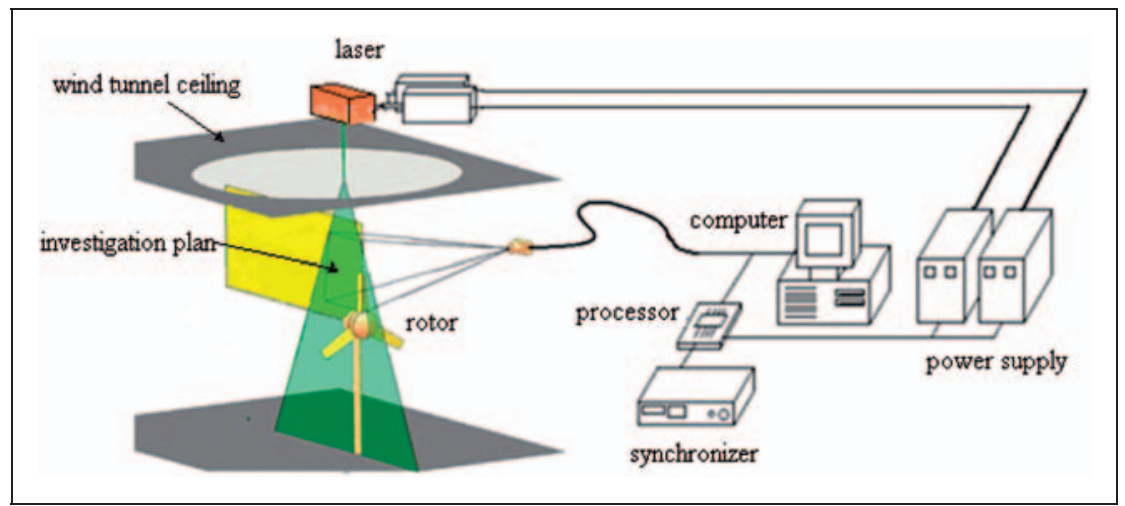

Figure 4. Experimental test bench by PIV.

needed for a good measure. The digital image processing is handled by Dantec Dynamics Studio 2.21 software using an iterative multi-resolution. ${ }^{10}$

\section{Test procedure}

The lasers were positioned above the test section on the Plexiglas transparent part. The PIV equipment was placed outside the test section to obtain an undisturbed flow. Seeding is done with the generator of droplets of olive oil into the diffuser of the blower. An optical encoder was used to target the rotating target glued on the hub on one hand and make a timing reference signal indicating the angular position of the rotor on the other hand. This signal can also control the trigger of laser shots and shooting images. Taking pictures is triggered when the axis of the blade is parallel to the plane of acquisition. This plan, which is the PIV laser sheet, is in the yawed position compared to the axis by the wind flow of an angle equal to the yaw angle of the rotor.

To explore the wake of the wind drift, several yaw angles are used, the initial position corresponding to the position of the axis of the test section which coincides with the axis of rotation of the wind turbine. The scale of the windows and their position with regard to the rotor are defined using a test pattern placed in the plane of exploration after each test series. After obtaining 200 images, they are processed using software from Dantec Dynamics.

The power of the wind turbine rotor is measured directly on the shaft using a torque meter: torque transducers, HBM T20WN model with VK20 terminal box. The tests will be conducted for different values of the velocity of rotation to define the characteristic curve of the rotor and power coefficient as a function of the tip speed ratio.

\section{Experimental results}

\section{Measuring the power of the wind turbine}

The torque meter is installed on the rotor shaft torque (measurement). The accuracy of the measured torque is $0.2 \%$. The velocity is measured by the optical encoder located on the mast of the wind turbine. The signals from these instruments are transmitted to a processing system using Labview software. This software processes the data and gives us the measured torque and the power measured on the computer. The power coefficient is given by

$$
C_{p}=\frac{P_{\text {measured }}}{P_{\text {available }}}
$$

where $P_{\text {measured }}$ is the power measured during the experiment and $P_{\text {available }}$ the available power, defined by equation (2)

$$
P_{\text {available }}=\rho_{\text {air }} \times \frac{V^{3}}{2} \times A
$$

where $\rho_{\text {air }}$ is the density of air. The temperature in the wind tunnel during the measurements is constant. A is the flow section of the test section of the wind tunnel and $V$ the measured velocity of the flow in the wind tunnel. The specific velocity is defined by equation (3)

$$
\lambda=\frac{\pi \times N \times D}{60 \times V}
$$

where $N$ is the rotational velocity of the rotor in $\mathrm{r} / \mathrm{min}$ and $D$ the rotor diameter. 


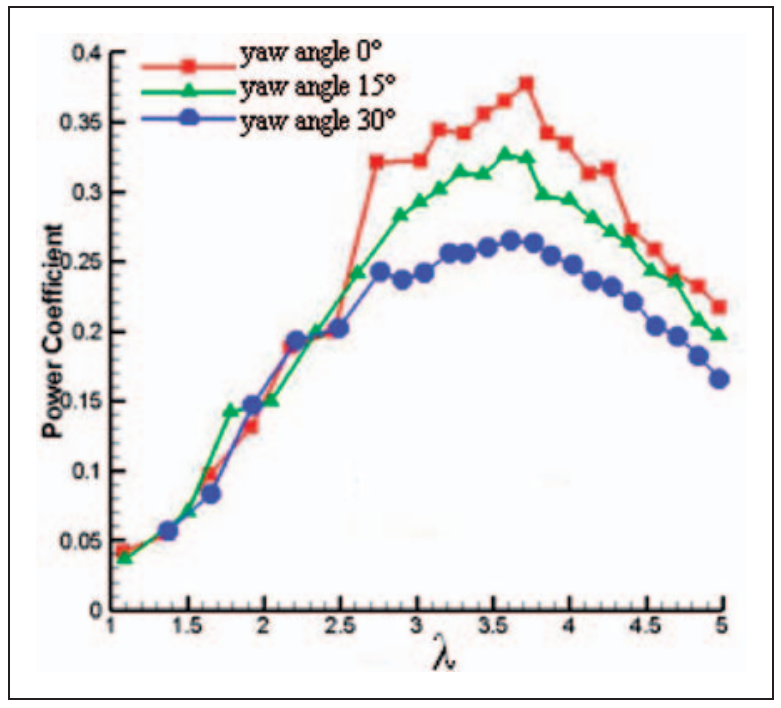

Figure 5. Power coefficient as a function of tip speed ratio.

\section{Comparison of power measurements of wind power}

The rotational velocity of the turbine is varied from 900 to $1800 \mathrm{r} / \mathrm{min}$ for a flow velocity of $9.22 \mathrm{~m} / \mathrm{s}$. This corresponds to a variation of the tip speed ratio $(\lambda)$ of 1 to 5 . Control of the rotational velocity was provided by a rheostat connected to the output of the electrical generator.

Figure 5 shows the variation of power coefficient based on the specific velocity of the studied wind turbine. For low values of this velocity, the power coefficient varies almost in the same manner for an axial flow or in the yawed position. The maximum values of power coefficient are reached for a value of tip speed ratio of around 3.65, which corresponds to a rotational velocity of $1296 \mathrm{r} / \mathrm{min}$. Dimitrov and Lazarov ${ }^{11}$ proves that the low solidity produces a broad flat curve which means that the power coefficient will change very little over a wide tip speed ratio range but the maximum power coefficient is low because the drag losses are high. Consequently, it is clear that the studied rotor misses solidity because the original wind turbine rotor had six blades. The maximum power coefficient is 0.377 for an axial flow. This power coefficient drops to a value of 0.265 , which corresponds to a loss of $30 \%$ when the rotor is yawed at an angle of $30^{\circ}$.

The yawed rotor is less efficient than the non-yawed one. In the yawed condition, even in a steady wind, the angle of attack on each blade is continuously changing as it rotates and so the loads on the rotor blades are fluctuating. The changes in angle of attack mean that the blade forces cause not only a thrust in the axial direction but also moments about the yaw and tilt axes. Even if the rotor is operating with a uniform induced velocity over the rotor disc when aligned with
Table I. Comparison of power coefficient.

\begin{tabular}{lll}
\hline Yaw angle & $C_{p}$ experimental & $\begin{array}{l}C_{p} \text { calculated }= \\
C_{p} \times \cos ^{3} \Psi\end{array}$ \\
\hline $15^{\circ}$ & 0.34 & 0.342 \\
$30^{\circ}$ & 0.25 & 0.246 \\
\hline
\end{tabular}

a steady wind, once the rotor is misaligned, the induced velocity varies both azimuthally and radially.

\section{Application of the momentum theory}

The application of the momentum theory to an actuator disc representing a yawed rotor is an alternative. The momentum theory is only capable of determining an average induced velocity for the whole rotor disc but, although in the non-yawed case, the restriction was relaxed to allow some radial variations, it would not be appropriate to do this in the yawed case because the blade circulation is also changing with azimuthal position. $^{11}$

In this theory, to find the maximum value of the power coefficient in the yawed flow, the $\cos ^{3}$ law is a rule that is commonly used for power assessment. The comparison of the experimental data to the results of the momentum theory is presented in Table 1 .

The comparison of these results confirms the application of the rule of $\cos ^{3}$ law given by this theory. If a theory is going to be of any help in the design process, it must be able to determine the induced velocity at each blade element with a satisfactory accuracy. The satisfactory calculation of blade forces is as important as the estimation of the power.

\section{Investigation of the downstream wake of the wind turbine}

In this case, the tests are performed for rotational velocities $1296,1345,1561$, and $1800 \mathrm{r} / \mathrm{min}$ and yaw angles $0^{\circ}, 15^{\circ}$, and $30^{\circ}$. Throughout these tests, the wind velocity in the wind tunnel is $9.3 \mathrm{~m} / \mathrm{s}$.

On that condition, the Reynolds number is $3 \times 10^{5}$. Modern airfoils of wind turbines are always selected for better aerodynamic efficiency so that the Reynolds number is everywhere higher than the critical Reynolds number, which is of the order $10^{5}-10^{6}$ for NACA airfoil ${ }^{12}$ for instance. We recall that there is a relative Reynolds number for each section of blade.

Images are taken to measure the velocity field in the azimuthal plane which passes through the blade axis. Figure 6 shows a raw image taken in a window of $2048 \times 2048$ pixels directly behind the rotor in a vertical position of the blade. This image shows the blade 


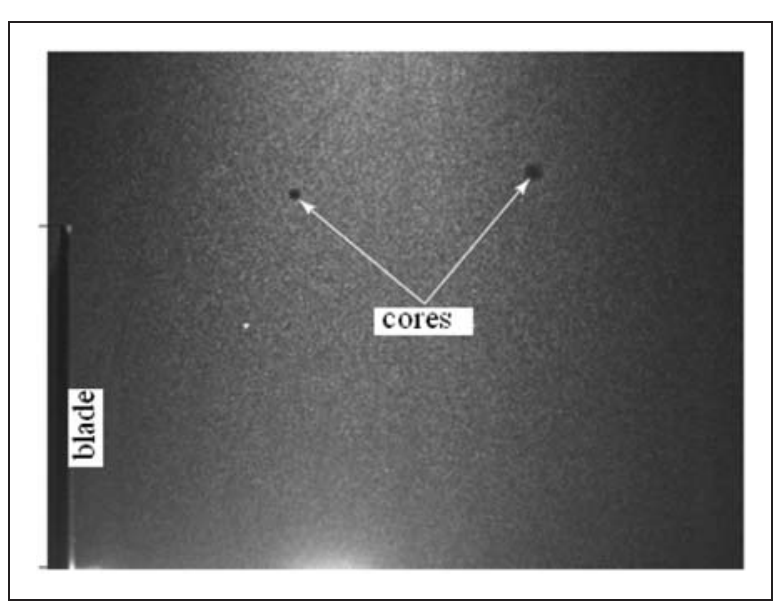

Figure 6. Raw image of the instantaneous velocity field.

(right) and the tubes' vortex cores from the ends of the other blades.

Because of the induced velocity by vortex tubes, which displaces the particles in the center of the core, the image shows a black circle with a lack of illuminated particles. The processing of the raw images gives the instantaneous and average velocity fields. Having obtained a sufficient number of images by PIV, the treatment of these images will be done by a multi-resolution iterative algorithm, see Susset et al. ${ }^{10}$ for more details.

\section{Analysis of results of the downstream wake exploration}

We start with the representation of the instantaneous velocity fields obtained by processing a raw image. Figure 7 shows the instantaneous velocity field corresponding to the raw image, already shown in Figure 6. This field shows the increase in the diameter of the tube streamline as a result of decelerating the flow created by the wind turbine, as predicted by the theory of FroudeRankine. ${ }^{11}$ We also see clearly the vortices emanating from the hub and blade tip in the exploration plan. To get the average velocity field, we averaged the resultant instantaneous field of series of 200 images. Figure 8 shows the average velocity field in an area of $300 \times 300 \mathrm{~mm}^{2}$. It is worthy to note that the review of successive fields over time shows a fluctuation in the position of the vortices cores relative to the plane of rotation.

This fluctuation is due to the temporal variation of the rotor power. It may be noted that the radial fluctuation of the cores weakly depends on their axial positions. On the other hand, axial flutter increases rapidly, because this flutter is amplified by the number of the steps taken. Thus, the average velocity field is not entirely representative of the wake development.

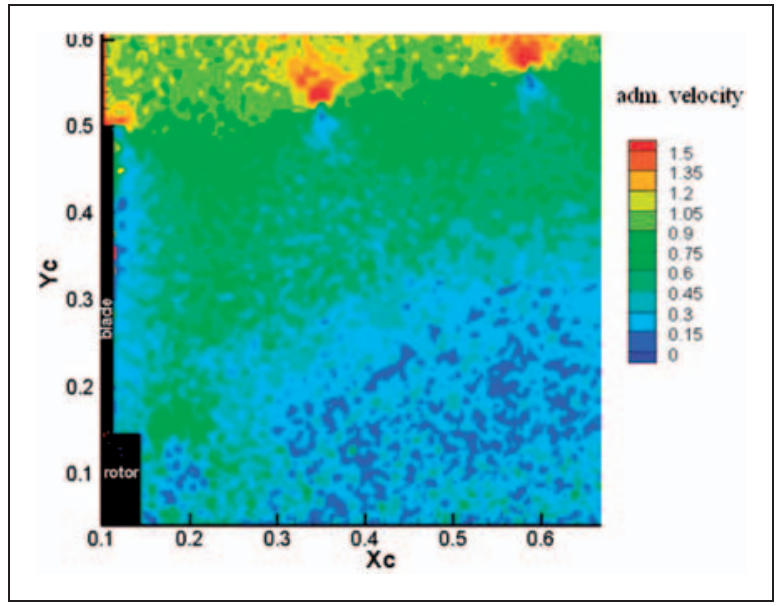

Figure 7. The instantaneous velocity field.

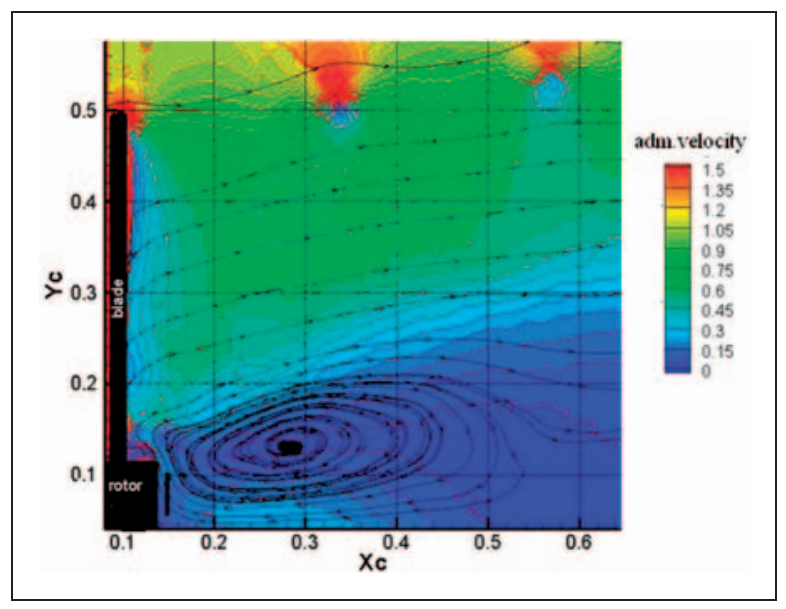

Figure 8. Averaged velocity fields for $\lambda=3.65$; wind turbine without yawed.

Figure 8 illustrates perfectly the tip vortex development from each blade and tip vortices. Note also the enlargement of the section of trail along the direction of the wind away from the rotor plane. This clearly shows why models that assume a constant diameter of vortex wake do not get good results.

Analysis of rotor wake shows that the hub is a source of disturbance and strong aerodynamic unsteadiness. This comes from the shape of bulky hub which contains the generator. We cannot see the influence of the support column on the wake downstream of the rotor in the exploration of the wake, and this is because only the superior part of the wake of the rotor is presented.

The vortices flow is divided into two parts, an inner part where the axial velocity is decelerated by vortices and an outer part where the speed is accelerated by the vortices. ${ }^{12}$ The influence of vortices may confirm the 


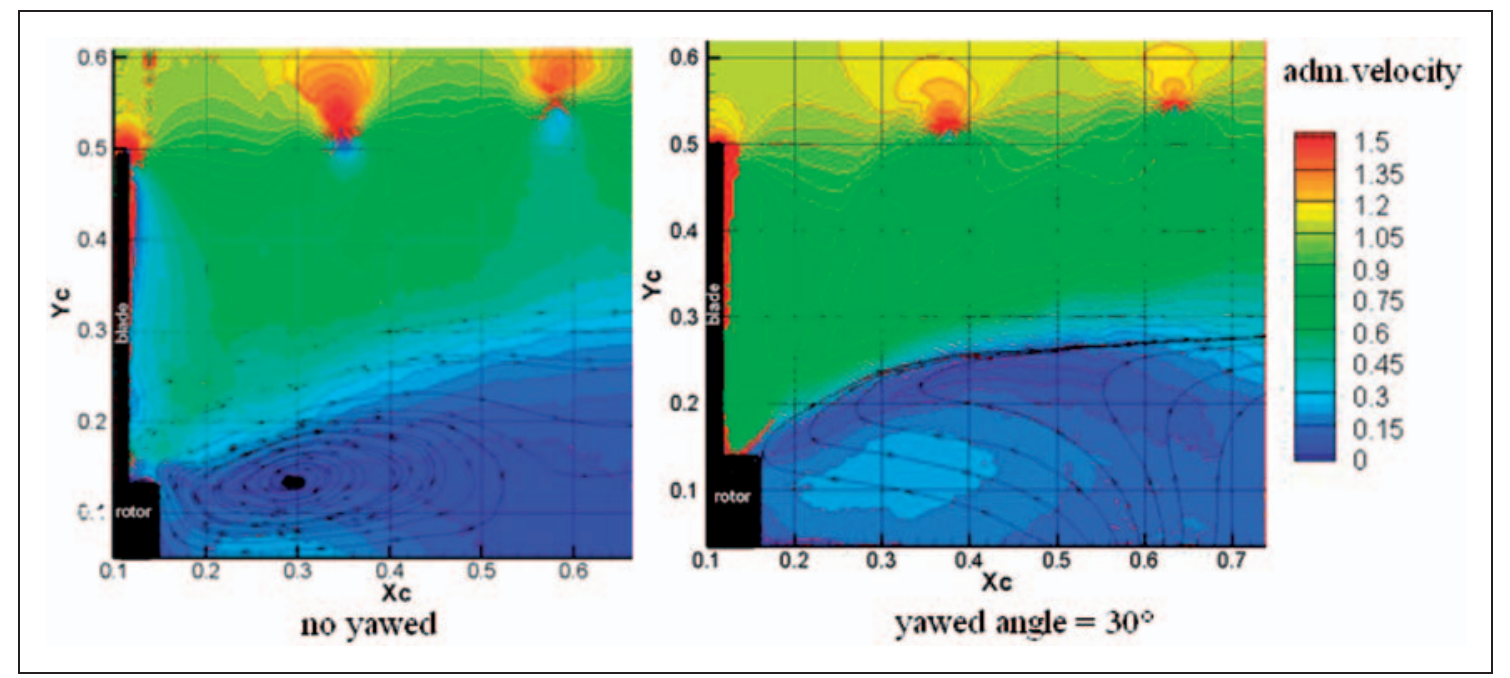

Figure 9. Averaged velocity fields depending on the yaw angle.

assumptions of the Prandtl eddy model. Thus, the position of vortices could be localized and determined.

\section{Influence of yaw angle on the downstream wake of the turbine}

Previous explorations have allowed us to visualize the tip vortex emitted from the tip of the blades and the rotor vortex for axial flow. Tests are performed to show the influence of variation of yaw angle on the downstream wake of the rotor. The yaw angle chosen for these tests is $30^{\circ}$ with a wind turbine rotational speed of $1296 \mathrm{r} / \mathrm{min}$. At this speed, the power losses are important for our yawed wind turbine when compared with the wind turbine without yaw (Figure 5). We kept the same wind speed of $9.3 \mathrm{~m} / \mathrm{s}$ to make a comparison between the wake of an axial flow and yawed wind turbine. Figure 9 shows the averaged velocity fields and (for upstream wind) dimensionless downstream of the rotor for a wind turbine without (axial flow) and with yaw. In both cases, we observe an increase in the streamline diameter. This is the result of the decelerating flow created by the wind turbine; this deceleration is the result of the operation of the rotor as predicted by the theory of Froude-Rankine. ${ }^{13}$

This is distinctive when the turbine is yaw, where one observes that the hub vortex increases in size and that vortex zone tends to move from the hub to the far wake in the wind direction. The hub leads to the blockage of the largest yaw flow compared to that of the axial flow. Consequently, a significant deceleration of the flow will appear behind the hub, which gives a reason for the existence of larger aerodynamic interactions responsible of the power loss and noise generation.

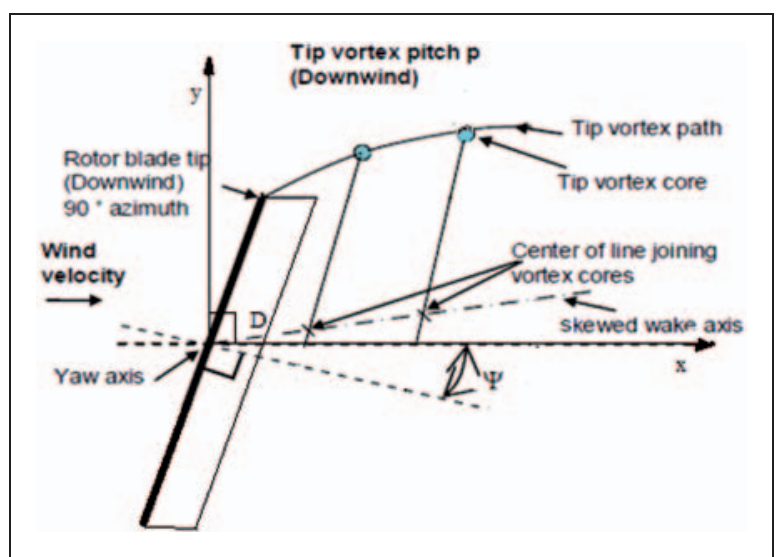

Figure 10. Position of tip vortex cores in a yawed rotor.

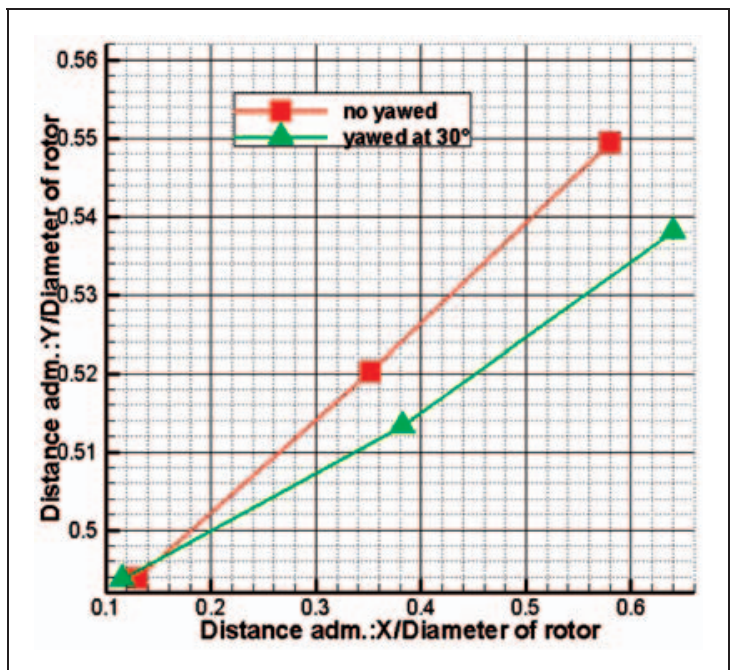

Figure II. Variation of the position of tip vortices depending on the yaw angle. 


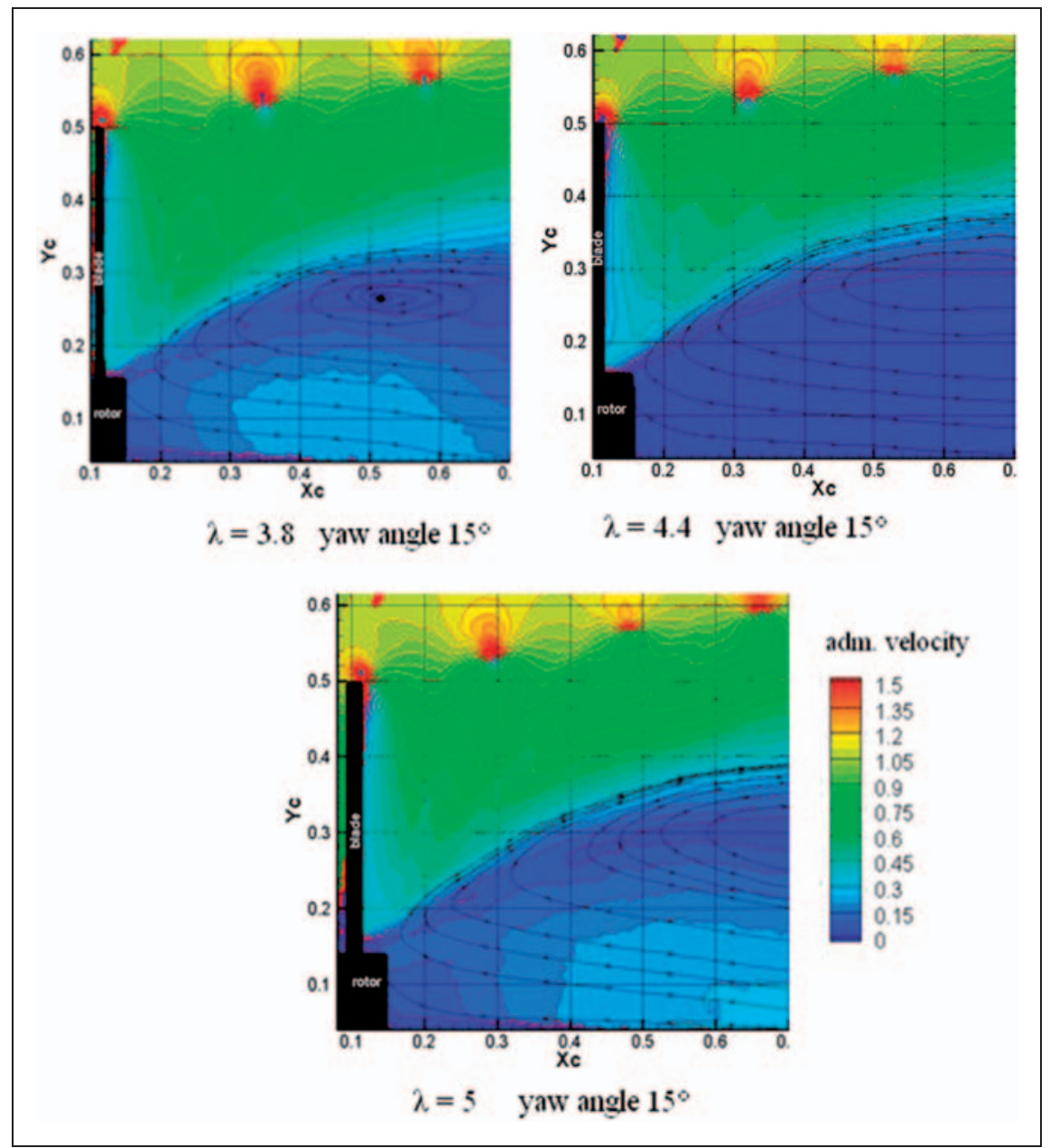

Figure 12. Averaged velocity field as a function of rotational speed, yaw angle $15^{\circ}$.

Figure 10 shows the positions of the tip vortex core, center of the line joining the vortex cores, and the yawed wake axis. Figure 11 shows that the variation of the tip vortex diameter is less important for the yawed wind turbine than the wind turbine with an axial flow. The decrease in diameter is $0.05 y / D$ on a distance of $0.6 x / D$ downstream of the rotor. So, the diameter of the vortex tube decreases, which proves that there is a loss of the recovered power in the yawed wind turbine case. The decrease in the vortex intensity of the third blade appears while calculating the average instantaneous field.

We can also see that the distance between the two consecutive vortex tubes from the blade tips changes significantly. This distance increases gradually; it reaches the maximum value of $0.06 x / \mathrm{D}$. The wake is less important in the case of yaw flow and shows that the wind turbine does not get enough kinetic energy from the wind as compared with a wind turbine without yaw. This power loss is confirmed by the previous power measurements.

\section{Influence of rotational velocity of the rotor}

Tests are performed to show the influence of varying the rotational velocity of the rotor on the wake downstream the turbine in the yawed flow. The chosen velocities for these tests are: 1345,1561 , and $1800 \mathrm{r} / \mathrm{min}$ for a wind speed of $9.3 \mathrm{~m} / \mathrm{s}$. The yaw angle of the wind turbine is $15^{\circ}$. Figure 12 shows the average velocity fields downstream the rotor for the yawed wind turbine. When the rotational speed of the yawed wind turbine increases, the wake downstream changes and the vortex zone of the hub tends to move away from the rotor. The size of this zone also increases with increasing the wind turbine rotational velocity. We can easily see in Figure 13 the decrease of the spacing between the two consecutive vortex tubes from the tip of the blades with an increase in the diameter of the vortex when the rotational velocity of the wind turbine increases. Indeed, during an increase in power consumption, average velocity in the wake decreases, leading to a step decrease and not the vortices. ${ }^{14}$ The continuity equation dictates 


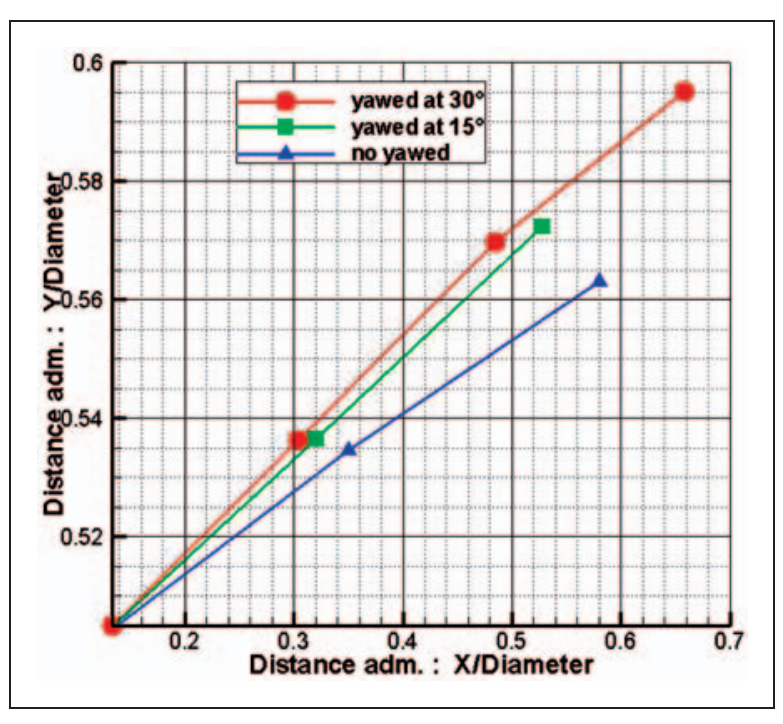

Figure 13. Variation in the position of vortices depending on the speed of the wind turbine.

that the radius of the streamline tube increases and the vortices move outward. The increase of diameter is $0.03 y / D$ at a distance of $0.68 x / D$ downstream of the rotor. This change in the position of vortices is increase with the wind turbine rotational velocity. However, the variation of the diameter of the tip vortices increases only from $0.002 y / D$ for a tip speed ratio of 4.4 . In other words, from a rotational velocity of $1561 \mathrm{r} / \mathrm{min}$, the power does not vary as we increase the rotational velocity of the wind turbine.

\section{Conclusions}

In this study, the power measurements show that the wind turbine power falls in the yawed condition. These data show that the active control of yaw angles could be an advantage to maintain the wind turbine power. The PIV technique is applied successfully to the study of the downstream wake of a HAWT. The results show that the vortex radius from the blade tips is not constant as assumed in the theory of linear helices. In reality, the diameter of the flow streamline increases as the simple theory of Froude-Rankine predicted. The measurements revealed that the influence of the variation of the yaw angle and the variation of the yawed wind turbine rotational velocity on the wake downstream is important. Instability of the blade tip vortex is also noteworthy. Because of these fluctuations, the instantaneous velocity field contains a lot of information.

The quality of data allows the use of these results as a reference for CFD. However, experimentally, it is difficult to obtain a sufficient spatial and temporal resolution to explore the wake development at a more important distance. For the moment, the experiment for a velocity field at a large band is out of the current experimental resources.

\section{Funding}

This research has been financed by the University of KhemisMiliana - Algeria.

\section{References}

1. Parkin P, Holmand R and Medici D. The application of PIV to the wake of a wind turbine in yaw. In: Proceedings of the 4th international symposium on particle image velocimetry, Gottingen, 17-19 September 2001, KTH Mechanics, SE-10044 Stockholm, Sweden.

2. Smith GH, Grant I, Liu A, et al. The wind tunnel application of particle image velocimetry to the measurement of flow over a wind turbine. Wind Eng 1991; 15(6): 301-317.

3. Grant I and Parkin P. A DPIV study of the trailing vortex elements from the blades of a horizontal axis wind turbine in yaw. Exp Fluids 2000; 28(4): 368-376.

4. Grant I, Mo M, Pan X, et al. An experimental and numerical study of the vortex filaments in the wake of an operational horizontal-axis wind turbine. J Wind Eng Ind Aerodyn 2000; 85: 177-189.

5. Massouh F, Dobrev I, Dejean F, et al. Etude du sillage d'une éolienne à axe horizontal. In: 16ème Congrès Français de Mécanique, CFM 2003, Nice, France, 1-5 September 2003.

6. Massouh F and Dobrev I. Investigation of wind turbine near wake. In: International conference on jets, wakes and separated flows, ICJWSF-2005, Toba-shi, Mie, Japan, 5-8 October 2005, pp.513-518.

7. Massouh F and Dobrev I. Exploration and numerical simulation of wind turbine wake. ISJAEE 2008; 6(62): 163-168.

8. Dobrev I, Maalouf B, Troldborg N, et al. Investigation of the wind turbine vortex structure. In: 14th international symposium on applications of laser techniques to fluid mechanics, Lisbon, Portugal, 7-10 July 2008, pp.1-10.

9. Schon J-P, Fournel T, et al. Mesures de caractéristiques d'écoulement par imagerie numérique. R 2162 éditions techniques de l'ingénieur - France.

10. Susset A, Most JM and Honoré D. Développement et validation d'un algorithme de super-résolution par corrélation directe pour la PIV: méthodes d'accélération du traitement. In: 8eCongrés Francophone de Vélocimétrie Laser, Orsy, France, 17-20 September 2002.

11. Dimitrov D and Lazarov V. Source d'énergie renouvelables. Université technique de Sofia, Bulgarie, 1999.

12. Jourieh M. Développement d'un modèle représentatif d'une éolienne afin d'étudier l'implantation de plusieurs machines sur un parc éolien. Thèse, L'ENSAM, 2007.

13. Burton T, Sharpe D, Jenkins N, et al. Wind energy handbook. England: John Wiley \& sons, 2001, p.98, 174.

14. Le Gourieres D. Les Eoliennes. Théorie, conception et calcul pratique. Année: Editions du moulin cadiou, 2008. 
Appendix

Notation

$\begin{array}{ll}A & \text { rotor swept area } \\ c & \text { blade cord } \\ C_{p} & \text { pressure coefficient } \\ D & \text { blade diameter } \\ N & \text { rotational velocity of the rotor } \\ P_{\text {available }} & \text { power calculated }\end{array}$

$P_{\text {measured }}$

V

W

$x, y$

$\Delta$

$\lambda$

$\rho$

$\Psi$ power measured

measured velocity

relative velocity

axial directions

difference

tip speed ratio

air density

yaw angle 